\title{
Alterações sistêmicas na erupção dentária decídua
}

\author{
Systemic changes in the deciduous dental eruption \\ Cambios sistémicos en la erupción dentaria decidua
}

Recebido: 10/03/2021 | Revisado: 17/03/2021 | Aceito: 20/03/2021 | Publicado: 28/03/2021

\author{
Maria Luisa Faria Barroso \\ ORCID: https://orcid.org/0000-0002-2818-6594 \\ Universidade Potiguar, Brasil \\ E-mail: luisafariaa@outlook.com \\ João Paulo de Lima Vieira \\ ORCID: https://orcid.org/0000-0003-1836-3865 \\ Universidade Potiguar, Brasil \\ E-mail: juaopaulodelima@hotmail.com \\ Maria Eunice Medeiros da Silveira Neta \\ ORCID: https://orcid.org/0000-0001-9003-6768 \\ Universidade Potiguar, Brasil \\ E-mail: Eunice_medeiros@hotmail.com \\ Airton Coimbra Monteiro de Medeiros Rodrigues \\ ORCID: https://orcid.org/0000-0002-7316-4968 \\ Universidade Potiguar, Brasil \\ E-mail:airton_cmmr@hotmail.com \\ Jaderson Felipe Santos Dantas \\ ORCID: https://orcid.org/0000-0002-6097-0936 \\ Universidade Potiguar, Brasil \\ E-mail: jaderson.dantas@gmail.com \\ Letícia Batista da Siva \\ ORCID: https://orcid.org/0000-0001-5153-8589 \\ Universidade Potiguar, Brasil \\ E-mail: leticiabatistaodonto@gmail.com \\ Pedro Gabriel de Paiva Paulino \\ ORCID: https://orcid.org/0000-0003-1164-252X \\ Universidade Potiguar, Brasil \\ E-mail: pedrogabrielpaiva2@gmail.com \\ Lucas Murelli de Sá Revorêdo \\ ORCID: https://orcid.org/0000-0001-6861-789X \\ Universidade Potiguar, Brasil \\ E-mail: revoredolucas123@gmail.com \\ Ana Larissa Fernandes de Holanda Soares \\ ORCID: https://orcid.org/0000-0002-3740-7862 \\ Universidade Federal do Rio Grande do Norte, Brasil \\ E-mail: pedrolauramafaldo@gmail.com
}

\begin{abstract}
Resumo
A relação entre a erupção dentária e o aparecimento de manifestações locais e gerais em crianças tem sido um assunto controverso no meio médico e odontológico no que diz respeito à saúde infantil. A pesquisa tem como objetivo verificar a associação entre as manifestações locais e sistêmicas e o período de erupção da dentição decídua em crianças de 4 meses a 4 anos, acompanhadas por Equipe de Saúde Bucal da Estratégia Saúde da Família do município de São Gonçalo do Amarante / RN. Foram entrevistadas 55 mães por meio de um questionário contendo questões objetivas sobre dados gerais de identificação e sobre os sinais e sintomas relacionados à erupção dentária. Os resultados mostraram que $75 \%$ das crianças analisaram sintomatologia durante a erupção dos elementos dentais decíduos e os sintomas mais relatados foram aumento da salivação, febre e diarreia. A maior sintomatologia (62\%) foi entre 4 meses a 1 ano de idade. Em relação à conduta diante sintomas, $44 \%$ dos entrevistados relataram que apenas acompanham a evolução, sem procurar o dentista. Conclui-se, portanto, que durante a erupção dos dentes decíduos, manifestações locais e / ou sistêmicas são percebidas pelos responsáveis, principalmente antes do primeiro ano de vida da criança.
\end{abstract}

Palavras-chave: Erupção dentária; Decídua; Manifestações orais; Odontopediatria.

\footnotetext{
Abstract

The relationship between tooth eruption and the appearance of local and general manifestations in children has been a controversial subject in the medical and dental environment with regard to child health. The search aims to verify the association between local and systemic manifestations and the period of eruption of primary dentition in children aged
} 
4 months to 4 years, accompanied by the Oral Health Team of the Family Health Strategy of the municipality of São Gonçalo do Amarante / RN. 55 mothers were interviewed through a questionnaire containing objective questions about general identification data and about signs and symptoms related to tooth eruption. The results lower than $75 \%$ of the children analyzed symptoms during the eruption of the deciduous dental elements and the most reported symptoms were increased salivation, fever and diarrhea. The greatest symptomatology (62\%) was between 4 months and 1 year old. Regarding the conduct in the face of symptoms, $44 \%$ of the interviewees reported that they only follow the evolution, without looking for a dentist. It is concluded, therefore, that during the eruption of deciduous teeth, local and / or systemic manifestations are perceived by those responsible, especially before the child's first year of life.

Keywords: Dental eruption; Deciduous; Oral manifestations; Pediatric dentistry.

\section{Resumen}

La relación entre la erupción dentaria y la aparición de manifestaciones locales y generales en los niños ha sido un tema controvertido en el ámbito médico y odontológico con respecto a la salud infantil. La investigación tiene como objetivo verificar la asociación entre las manifestaciones locales y sistémicas y el período de erupción de la dentición temporal en niños de 4 meses a 4 años, acompañados pelas Equipo de Salud Bucal de la Estrategia de Salud de la Familia del municipio de São Gonçalo do Amarante / RN. Se entrevistó a 55 madres mediante un cuestionario que contenía preguntas objetivas sobre los datos generales de identificación y sobre los signos y síntomas relacionados con la erupción dentaria. Los resultados mostraron que el 75\% de los niños tenía los síntomas durante la erupción de los elementos dentarios decíduos, y los síntomas más reportados fueron aumento de la salivación, fiebre y diarrea. La mayor sintomatología (62\%) fue entre los 4 meses y 1 año. En cuanto a la conducta ante los síntomas, el $44 \%$ de los entrevistados refirió que solo sigue la evolución, sin buscar dentista. Se concluye, por tanto, que durante la erupción de los dientes temporales los responsables perciben manifestaciones locales y / o sistémicas, especialmente antes del primer año de vida del niño.

Palabras clave: Erupción dental; Caduco; Manifestaciones orales; Odontología pediátrica.

\section{Introdução}

O processo de erupção dental pode ser definido como um movimento migratório, realizado por um dente em formação, do seu local de desenvolvimento dentro do processo alveolar para sua posição funcional na cavidade bucal. (Massler \& Schour, 1941).

O estágio eruptivo da dentição decídua estende-se, em média, do sexto ao trigésimo mês de vida da criança. Por volta dos 6 a 8 meses de idade inicia-se a erupção dos incisivos centrais, seguidos pelos incisivos laterais, primeiros molares, caninos e segundos molares, sendo que, de maneira geral, os dentes inferiores antecedem os superiores. (Koch, Mooder, Pousen, Rasmussen, 1995).

O irrompimento do primeiro dente decíduo por volta do sexto mês de vida constitui um marco significante na vida das crianças e dos pais. A relação da erupção do dente decíduo com o aparecimento de manifestações locais e sistêmicas tem sido relatada ao longo de vários anos e continua sendo assunto controverso entre médicos, cirurgiões-dentistas e pais. (Carpenter 1978).

De acordo com documentos antigos, o primeiro registro da relação entre distúrbios sistêmicos e erupção dentária foi descrito por Hipócrates (460-361 a.C.). Ele associou febre, distúrbios gastrintestinais, aumento da salivação e perda de apetite com manifestações próprias da erupção dentária (Kugelmass, 1960).

Com base na literatura, três linhas de pensamento importantes da possível relação entre os sintomas clínicos e a erupção dos dentes decíduos podem ser identificadas: a erupção de dentes decíduos é um processo fisiológico, portanto, não traz sintomatologia; a erupção decídua é um processo patológico que traz sintomas muitas vezes graves, chegando a convulsões; e a erupção é um processo fisiológico, todavia, as atividades normais do organismo podem ter seu ritmo fisiológico alterado e manifestar o seu desequilíbrio sob a forma de sintomas (Neaderland, 1952).

A relação entre erupção dentária e o aparecimento de manifestações orgânicas locais e gerais nas crianças têm constituído um assunto polêmico no meio médico e odontológico. As manifestações orgânicas de ordem geral, observadas nas crianças durante a erupção dos dentes decíduos são: perturbações gastrintestinais, diarreia, vômito, infecções no trato 
respiratório, diminuição da resistência orgânica, tosse, corrimento nasal, distúrbios do sono, irritabilidade, febre, redução do apetite, urina com odor forte, coceira auditiva, dificuldade de movimento, convulsões e lesões cutâneas periorais. (Koch, et al. 1995; Abujamra, Ferreira, \& Guedes-Pinto, 1994; Silva \& Walter, 1997).

As manifestações orgânicas de ordem local, verificadas nas crianças, durante a erupção dos dentes decíduos são: aumento da sucção digital, bruxismo, inflamação da gengiva, eritema, edema e prurido gengival, eritema da face, irritação local traduzida pelo ato de morder e coçar, hiperemia da mucosa bucal, salivação excessiva, tumefações gengivais, herpes, cisto de erupção e úlceras bucais. Embora muitas vezes os dentes decíduos irrompam sem causar quaisquer sintomas ou sinais, em 2/3 de todas as crianças, sinais e/ou sintomas locais podem ser observados. (Koch, et al, 1995; Abujamra et al. 1994; Bengston \& Bengston 1994, Noronha, 1985).

$\mathrm{Na}$ fase de erupção dos dentes, a criança apresenta uma menor resistência e maior suscetibilidade a doenças e infecções, o que pode explicar uma coincidência entre a erupção dos dentes decíduos e sintomas gerais. A erupção não é suficiente para determinar esses sintomas, embora a erupção e tais sintomas possam ocorrer concomitantemente. (Carpenter, 1978; Kugelmass, 1960; Galili, Rosenzweig \& Klein, 1969).

Certamente qualquer relação de causa e efeito entre a erupção dos dentes decíduos e os distúrbios locais ou sistêmicos é difícil de ser estabelecida. Porém, as observações clínicas e os achados anamnésicos conduzem os profissionais de saúde que atendem crianças a uma posição cautelosa diante do assunto, uma vez que a ocorrência de manifestações locais ou sistêmicas relacionadas com o desequilíbrio do processo eruptivo depende da completa interação dos fatores pessoal-ambientais, os quais obviamente variam de criança para criança. (Noronha, 1985)

O objetivo da presente pesquisa é verificar a associação entre manifestações locais e sistêmicas e o período de erupção dos dentes decíduos em crianças na faixa etária de 4 meses a 4 anos, acompanhadas por uma Equipe de Saúde Bucal da Estratégia Saúde da Família do município de São Gonçalo do Amarante/RN. Além disso, identificar as manifestações locais e sistêmicas mais comuns durantes a erupção dos elementos decíduos, verificando em qual faixa etária o aparecimento das manifestações locais e sistêmicas são mais frequentes na dentição decídua e conhecer as atitudes tomadas pelos responsáveis em relação à sintomatologia apresentada durante a erupção dos elementos decíduos.

\section{Metodologia}

O trabalho trata-se de um estudo transversal descritivo exploratório. Foi realizado na Unidade Básica de Saúde da Estratégia Saúde da Família de Serrinha, localizada no município de São Gonçalo do Amarante/RN. A amostragem foi por conveniência e, portanto, não probabilística. Foram entrevistadas 55 mães ou responsáveis de crianças na faixa etária de quatro meses a quatro anos de idade acompanhadas no CD (crescimento de desenvolvimento) pelos profissionais da equipe. Foram incluídas mães ou responsáveis por crianças que estavam dentro da faixa etária estabelecidas, cujas crianças não apresentavam qualquer tipo de síndrome ou doença sistêmica que comprometesse o sistema imunológico. Foi realizada a assinatura do Termo de Consentimento Livre e Esclarecido (TCLE), o qual autoriza a participação na pesquisa. Mães cujas crianças apresentavam qualquer tipo de síndrome ou doença sistêmica que comprometesse o sistema imunológico foram excluídas da pesquisa.

Inicialmente foi realizado o primeiro contato com os profissionais da Unidade Básica de Saúde da Estratégia Saúde da Família de Serrinha, localizada no município de São Gonçalo do Amarante/RN, para apresentação do projeto e identificação do dia e horário em que as crianças do CD (Crescimento e Desenvolvimento) eram atendidas na Unidade Básica de Saúde. Foram aplicados questionários contendo perguntas objetivas sobre dados gerais de identificação e sobre os sinais e sintomas relacionados à erupção dentária. Dois entrevistadores ficaram responsáveis pela coleta de dados. Os dados foram analisados de forma descritiva, a partir de tabelas e gráficos. O programa utilizado foi o Excel 2007. O presente trabalho foi aprovado pelo 
Comitê de Ética da Universidade Potiguar (UnP) com o protocolo 1.575.841. A autorização para participar do estudo, por meio do termo de consentimento, foi obtida após os pais ou responsáveis serem informados das razões do estudo, deixando claro que os dados seriam mantidos em sigilo e a identidade dos indivíduos resguardada.

\section{Resultados}

No presente estudo foram entrevistadas 55 mães/responsáveis, com idade média de 26,4 (DP=6,11). A maioria (46\%) das crianças participantes da pesquisa estavam na faixa etária entre 1 - 2 anos de idade, $29 \%$ eram menores que 1 ano de idade e 25\% entre 3-4 anos. O sexo masculino (56\%) prevaleceu entre as crianças incluídas na pesquisa, sendo o sexo feminino com $44 \%$.

O percentual de mães ou responsáveis pelas crianças, por grau de escolaridade em Serrinha (São Gonçalo do Amarante/RN - 2016) foi maior parte de mães/responsáveis possuía apenas o ensino fundamental (51\%), ensino médio (38\%), ensino superior (9\%) e somente $2 \%$ relataram ser analfabetas.

Gráfico 1 - percentual da idade de crianças que foram a primeira vez ao cirurgião-dentista - Serrinha (São Gonçalo do Amante/RN 2016).

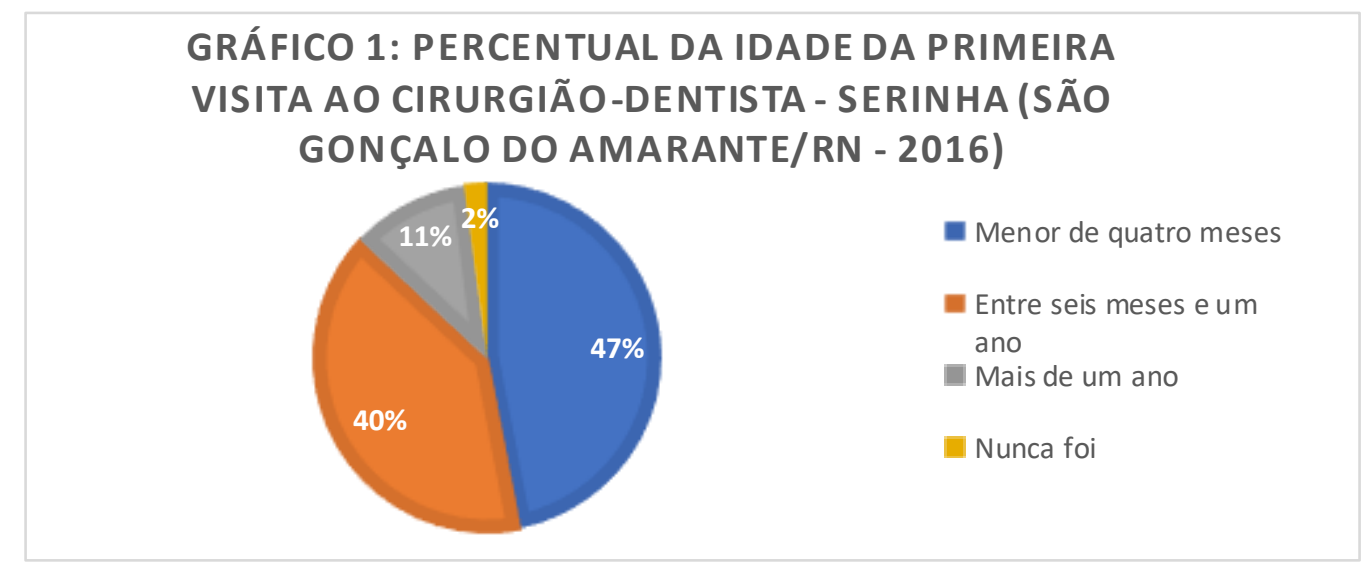

Fonte: autores.

O Gráfico 1 mostra que, maior parte das crianças (47\%) visitou pela primeira vez o cirurgiã-dentista antes dos 4 meses de idade. Enquanto que a parti da faixa etária de seis meses e um ano foi de $40 \%$, enquanto aquelas crianças que nunca foram ao cirurgião-dentista foi apenas $2 \%$ do percentual. 
Gráfico 2 - Sintomatologia apresentada pelas crianças durante o irrompimento dos elementos dentários decíduos - Serrinha (São Gonçalo do Amarante/RN - 2016).

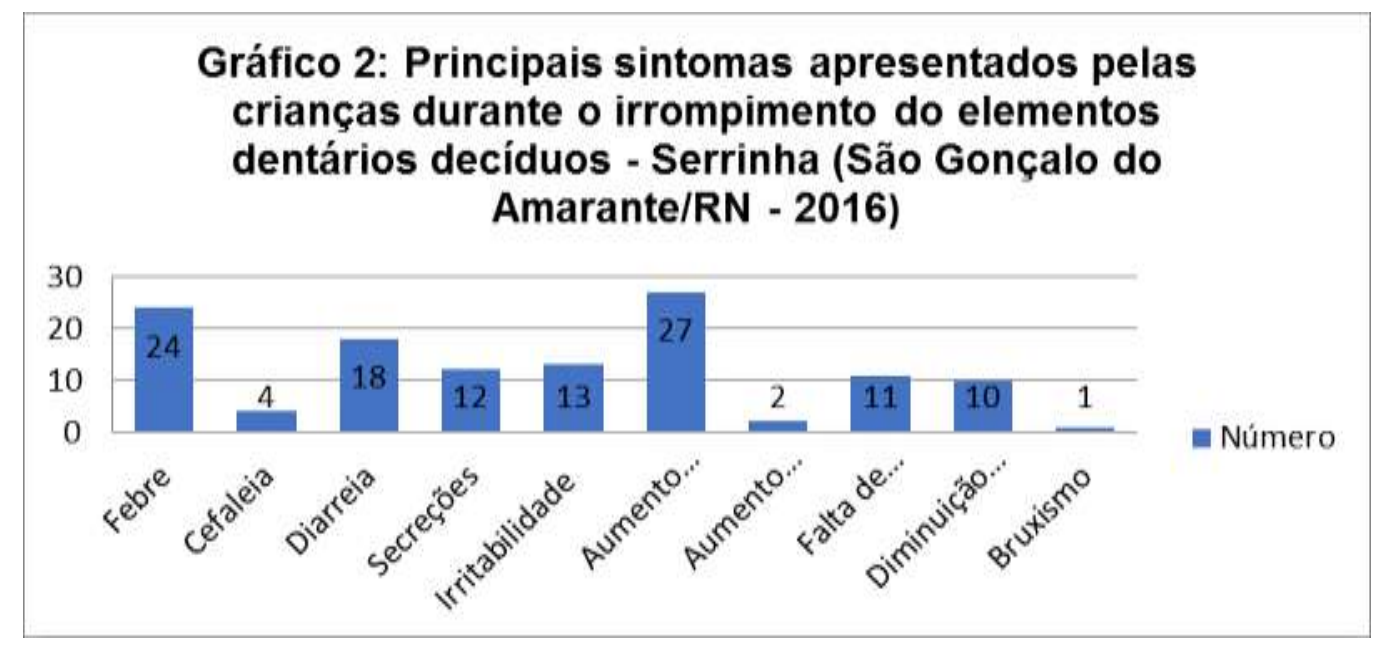

Fonte: Autores.

No Gráfico 2, mostra que a maior parte (75\%) das crianças analisadas apresentaram sintomatologia durante o irrompimento dos elementos dentários decíduos, e os sintomas mais relatados foram aumento da salivação (27), febre (24) e diarreia (18).

Gráfico 3 - Idade de ocorrência dos sintomas durante o irrompimento dentário - Serrinha (São Gonçalo do Amarante/RN 2016).

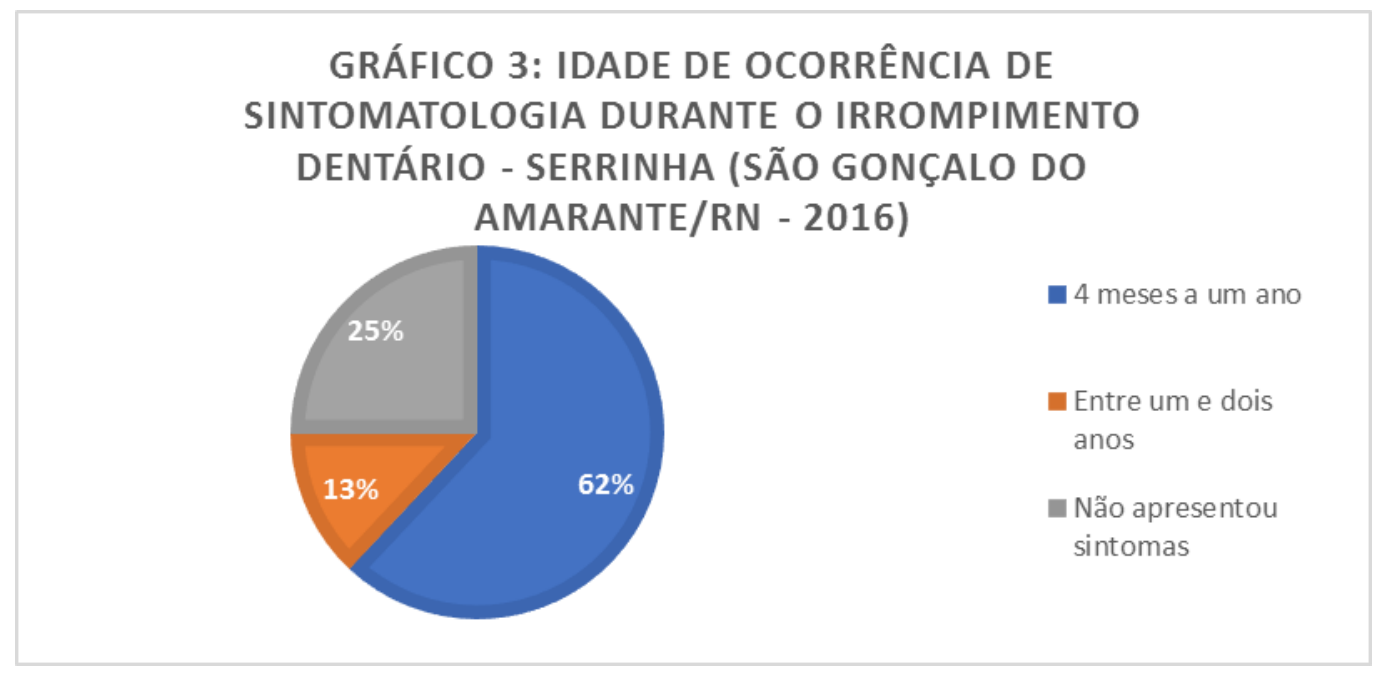

Fonte: Autores.

O Gráfico 3 expõe que o maior percentual (62\%) de sintomatologia durante o irrompimento dentário aconteceu na faixa etária entre 4 meses à 1ano. Enquanto que o menor percentual (25\%) não apresentou nenhum sintoma. 
Gráfico 4 - Percentual de mães/responsáveis orientadas sobre possibilidade de sintomatologia pelo cirurgião-dentista Serrinha (São Gonçalo do Amarante/RN 2016).

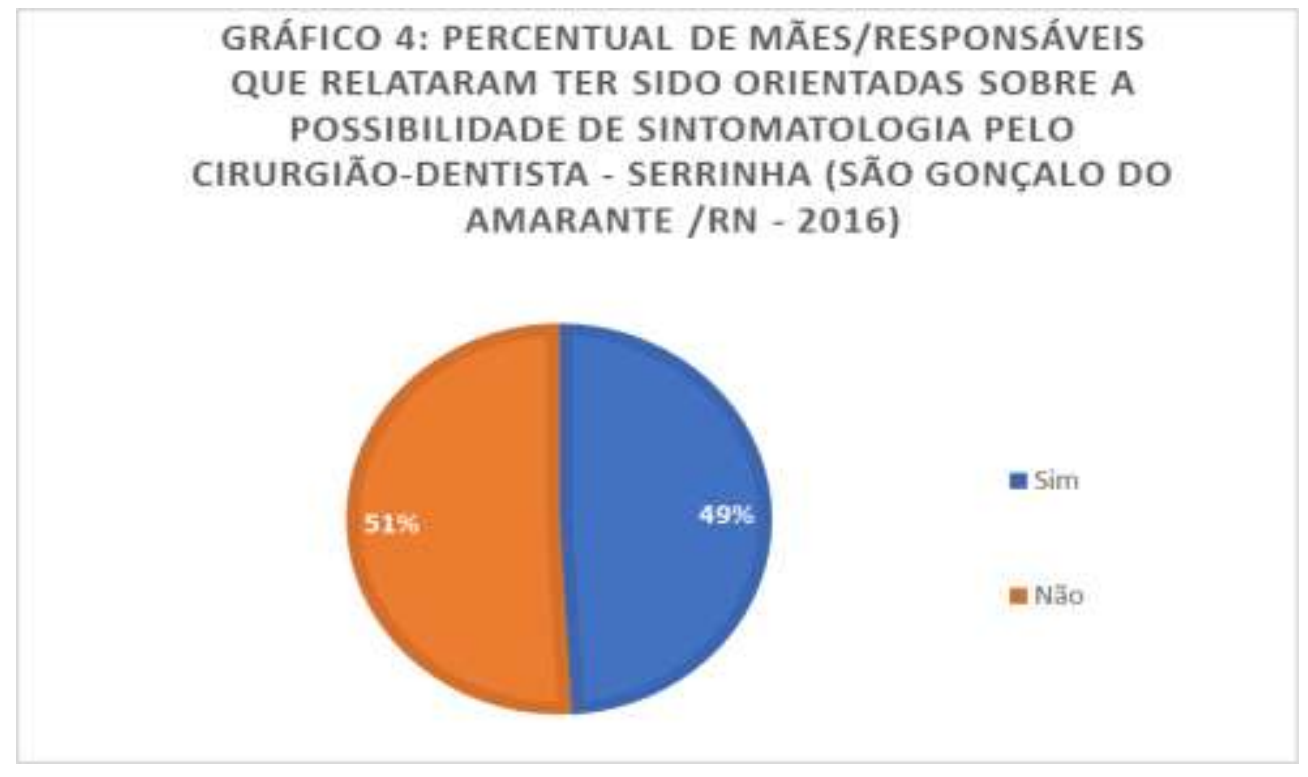

Fonte: Autores.

Observando o Gráfico 4, 49\% das mães/responsáveis relataram ter sido orientadas quanto a possibilidade de sintomatologia durante o irrompimento dos dentes decíduos, enquanto que 51\% relataram ter sido orientadas.

Gráfico 5 - Conduta de mães/responsáveis frente a sintomatologia durante o irrompimento dos dentes. Serinha (São Gonçalo do Amarante/RN - 2016).

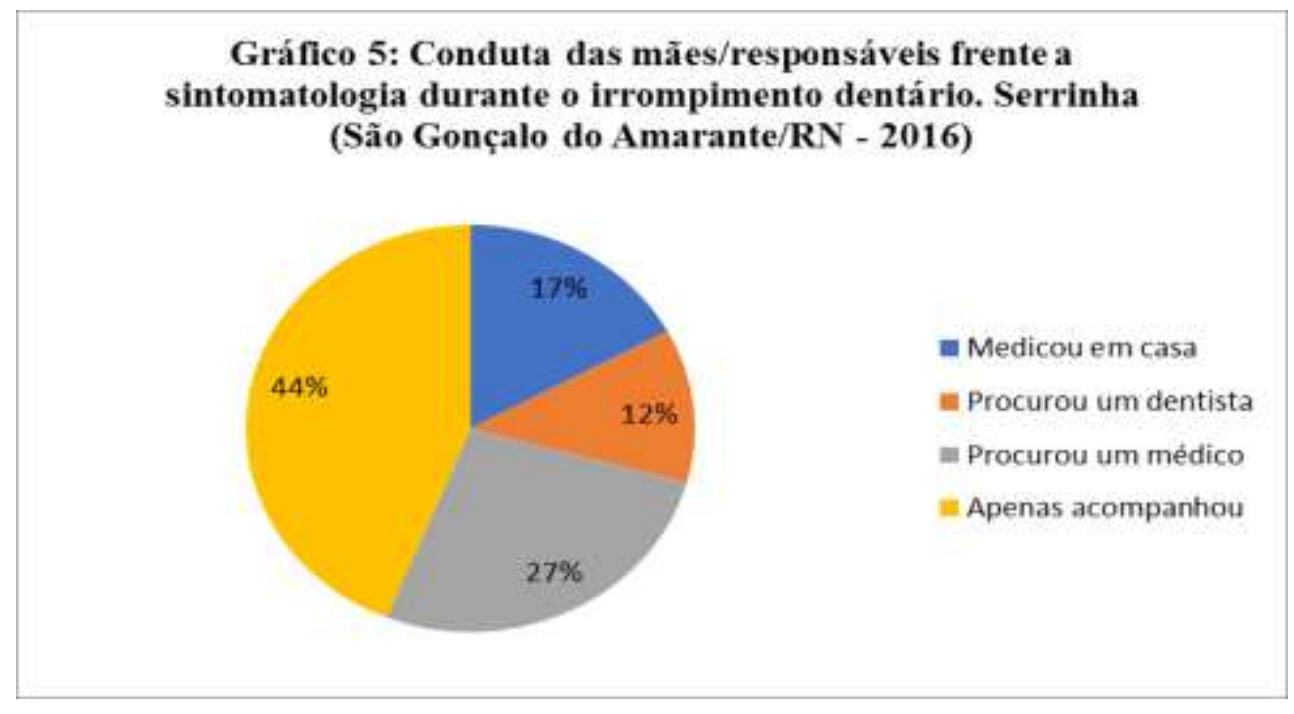

Fonte: Autores.

Em relação à conduta frente ao aparecimento de algum sintoma, $44 \%$ dos entrevistados informaram que apenas acompanharam a evolução, sem procurar um cirurgião-dentista, enquanto que $27 \%$ procurou um médico, $17 \%$ medicou em casa, e apenas $12 \%$ procurou um cirurgião-dentista (Gráfico 5). 


\section{Discussão}

A relação entre erupção dentária e o aparecimento de manifestações orgânicas locais e gerais nas crianças têm constituído um assunto polêmico no meio médico e odontológico. Parecem existir duas correntes principais, com diferentes opiniões em relação a esse tema.

A primeira acredita que a erupção é um processo fisiológico, e como tal, a sua associação com diarreia, febre, falta de apetite, erupção cutânea, coriza, aumento da salivação e outras alterações não é justificada, ocorrendo apenas uma coincidência entre erupção dental e o aparecimento dos distúrbios gerais, muitas vezes, a ele creditados. Os autores afirmam que dos 6 meses aos 2 anos de idade a criança sempre apresenta dentes em erupção, e o aparecimento de distúrbios orgânicos nessa época pode ser precipitadamente atribuído à erupção dentária (Assed, 2005).

$\mathrm{Na}$ segunda corrente, os autores acreditam existir uma relação bem evidente entre os sintomas locais e gerais e a erupção dental e citam que mesmo durante processos fisiológicos normais, tais como o parto, a menstruação e a digestão, o organismo pode ter seu ritmo fisiológico alterado e, assim, manifestar o seu equilíbrio sob a forma de sintomas. (Assed, 2005).

Considerando os resultados encontrados no presente estudo, é possível verificar que a maioria (46\%) das crianças participantes da pesquisa estavam na faixa etária entre 1 - 2 anos de idade. Segundo Assed (2005), o estágio eruptivo da dentição decídua estende-se, em média, do sexto ao trigésimo mês de vida da criança. Estando dentro da faixa etária estabelecida pela pesquisa.

Nessa pesquisa, o percentual maior de mães/responsáveis possuía apenas o ensino fundamental (51\%) e somente $9 \%$ relatou ter graduação. Dados da literatura sugerem uma forte relação entre o nível de escolaridade e a falta de informação das mães, que, apesar de possuírem conhecimentos básicos sobre saúde bucal, não consideraram a dentição decídua importante, valorizando assim a permanente, tendo como justificativa o fato de que os dentes decíduos serão substituídos em breve espaço de tempo. (Saito, Deccico \& Santos, 1999).

O sexo masculino prevaleceu entre as crianças incluídas na amostra. Porém, segundo Pinto et al. (1998) parece não haver variações relativas ao sexo, maturidade psicomotora da criança, altura corpórea e maturação esquelética.

Como mostra o Gráfico 1, a maior parte das crianças (47\%) visitou pela primeira vez o cirurgiã-dentista antes dos 4 meses de idade, comprovando o que a Academia Americana De Odontopediatria (2001) recomenda, a qual determina que a primeira visita ao cirurgião-dentista deva ocorrer no período compreendido entre a erupção do primeiro dente decíduo e o primeiro ano de vida da criança. Este comparecimento precoce ao consultório odontológico possibilitará o trabalho conjunto dos pais e da odontopediatria na prevenção de futuros problemas dentários. Ao analisar os resultados obtidos na "Bebê Clínica", Walter (1995), comprovou a efetividade de um programa de atendimento odontológico em bebês, observando que os melhores resultados foram alcançados naquelas crianças cujo primeiro atendimento ocorreu por volta dos seis meses de idade, coincidindo, portanto, com a erupção dos primeiros dentes decíduos. Ferreira, Kramer e Longoni (1999) relatam que as primeiras consultas da criança ao cirurgião-dentista devem ser encorajadas a realizarem-se durante o primeiro ano de vida, não mais aos dois ou três anos de idade como estava convencionado. Em acréscimo, segundo os autores, a visita odontológica ainda nos primeiros meses de vida é justificada, principalmente, pela possibilidade de prevenção de doenças, manutenção da saúde bucal e, também, pelo fato de as crianças crescerem ambientadas com consultórios odontológicos. Deste modo, as primeiras visitas devem fornecer uma introdução agradável, livre de ansiedade para os pais, de modo a estabelecer, com a ajuda da anamnese, um programa de prevenção que possa ser seguido pelos pais e pela criança. Constituem- em um marco na vida odontológica de um indivíduo e faz parte da busca de seu bem estar num âmbito maior: a saúde geral. (Fonseca et al, 1992).

A presente pesquisa mostrou que $75 \%$ das crianças apresentaram sintomatologia durante o irrompimento dos elementos dentários decíduos, confirmando o que diz Ferreira, Machado, Ardenghi e Praetzel (2009), uma vez que, de acordo 
com sua pesquisa, a maioria dos pais relatou a presença de manifestações sistêmicas e/ou locais, havendo forte evidência entre a erupção dentária decídua e manifestações (sinais e sintomas). Corroborando também com Medeiros et al. (2007), onde, de acordo com sua pesquisa realizada com médicos, relata que, dos médicos pediatras entrevistados, $76 \%$ acreditavam que o processo de erupção dentária pode, ocasionalmente, estar associado às manifestações sistêmicas e/ou locais, enquanto $24 \%$ acreditam não existir relação entre o processo de erupção e qualquer manifestação que possa eventualmente acontecer.

É possível constatar que no período de erupção dos dentes decíduos podem ocorrer manifestações clínicas relacionadas diretamente ou não com esses fenômenos. No presente estudo, dentre as dezesseis sintomatologias apresentadas no questionário, de acordo com o Gráfico 2, a maior prevalência de sintomas foi o aumento da salivação (27\%), seguido da febre $(24 \%)$ e diarréia (18\%). O aumento excessivo da salivação pode ser explicado por duas hipóteses, uma delas se refere à maturação das glândulas salivares e outra pela incapacidade de a criança deglutir corretamente. Bengton et al. (1988) e Abujamra et al. (1994), por sua vez, encontraram em seus trabalhos científicos a salivação aumentada como a principal alteração observada entre os pacientes pesquisados. Harndt e Weyers (1969), afirmaram que o aumento do fluxo salivar é devido ao fato de que a diferenciação das células especificas das glândulas salivares se faz somente ao final do segundo mês e, como o lactente não sabe reter essa secreção constante, escorre-se lhe da boca e se fala em "salivação aumentada", para relacioná-la infundadamente com a erupção dental. Tanasen (1968) associa o aumento da salivação como consequência do estimulo da sucção digital com friccionamento gengival, ato este intensificado durante a erupção dental. Contudo, Honig (1975) concorda que a salivação aumentada à época da erupção pode simplesmente significar o início da atividade das glândulas salivares que se dá dos três a quatro meses de idade. Diversos autores relacionam este comportamento a tentativa de alivio de sintomas locais como prurido ou dor.

A maioria dos autores encontrou associação significante entre erupção dentária e a febre, porém sem causa identificável. Sabe-se que há diminuição da imunidade humoral circulante da criança, conferida pela mãe por via placentária, e o estabelecimento da imunidade própria da criança, fazendo com que a maioria delas fique suscetível a várias infecções menores. (Mcintyre \& Mcintyre, 2002).

Em 1986, Benett e Spencer concluíram que em 84\% das crianças, a erupção dental é acompanhada de febre, ocasionada pelo vírus H.T, que é o causado de uma infecção primaria no início da vida da criança, sendo esta infecção subclínica, permanecendo o vírus em estado latente na crista alveolar. Galili, et al. (1969) salientaram que o dente, durante sua erupção, exerce pressão nos tecidos circunvizinhos, irritando o nervo trigêmeo, que estimula o centro de regulação da temperatura. Galili et al. (1969) também acredita que as erupções dentarias múltiplas constituem estresse suficiente para diminuir a resistência orgânica a infecções. Já segundo Leung (1989), durante a idade em que os dentes irrompem a criança é mais susceptível a infecções e doenças, porem isso não é causado pela erupção em si.

Jaber, Cohen e Mor (1992), notaram aumento estatisticamente significante na temperatura (acima de $37,5^{\circ} \mathrm{C}$ ) no dia em que o dente começa a irromper. Um estado febril de $37^{\circ} \mathrm{C}$ pode ser, muitas vezes, verificado nos bebês durante a fase de erupção dos dentes decíduos, que somente deve ser motivo de preocupação quando a febre for alta, e estiver associada a quadros de diarreia, vômitos ou erupções cutâneas.

Em consonância com os estudos já citados, é bem provável que exista uma relação entre diarreia e irrompimento dos dentes decíduos, porém há dificuldade em determinar clinicamente os casos de diarreias provocados por uma reação de caráter psicofisiológica e aqueles por contaminação bacteriana. Koch et al. (1995), acreditam que a própria inflamação local poderia tornar as crianças irritáveis, febris e com mudanças no peristaltismo intestinal. Entre o $4^{\circ}$ e o $12^{\circ}$ mês, geralmente ocorre o desmame e a introdução de novos alimentos fazem com que durante essa fase a crianças apresentem sintomas de diarreia, que apenas coincidem com o irrompimento de dentes. 
Coreil, Price e Barkey (1995), estudaram o reconhecimento de uma "diarreia de erupção dentária" por médicos pediatras da Flórida (EUA) e verificaram que a maioria deles (65\%) acreditava que a diarreia que ocorre na época da erupção dos dentes decíduos não está relacionada com esta entidade, mas sim com outros acontecimentos. Entre eles, os mais citados foram mudança dos hábitos alimentares, aumento da salivação e estresse. Enquanto que, Baume, Becks e Evans (1954), acreditavam má influência do hormônio da tiroide na erupção dentaria e sugeriram a possibilidade de existir relação entre os distúrbios sistêmicos associados ao irrompimento de dentes e as alterações hormonais. Sem dúvida a criança nos seus primeiros anos de vida extrauterina, está a todo momento experimentando emoções e sensações diferentes e novas, sendo o início do irrompimento de dentes em sua cavidade bucal, até então desdentada, uma dessas alterações, a qual poderá trazer ao pequeno ser uma situação estressante, responsável por alterações na fisiologia intestinal normal. (Morais-Filho et al. 1985).

No presente estudo, o Gráfico 3 expõe que o maior percentual (62\%) de sintomatologia durante o irrompimento dentário aconteceu na faixa etária entre 4 meses à 1ano. De acordo com Assed (2005), dos 6 meses aos 2 anos de idade a criança sempre apresenta dentes em erupção e o aparecimento de distúrbios orgânicos nessa época pode ser precipitadamente atribuído à erupção dentária. Visto que, esses valores se encontram dentro do padrão de erupção dentária decídua.

De acordo com o Gráfico 4, apenas 49\% das mães/responsáveis relataram ter sido orientadas quanto a possibilidade de sintomatologia durante o irrompimento dos dentes decíduos. Apesar de a população estar em um território assistido pela equipe da Estratégia Saúde da Família juntamente com a equipe de Saúde Bucal, uma parte significante das mães não tinha orientação em relação à erupção dental. De acordo com o Ministério da Saúde a equipe de Saúde Bucal na Estratégia Saúde da Família representa a possibilidade de criar um espaço de práticas e relações a serem construídas para a reorientação do processo de trabalho e para a própria atuação da saúde bucal no âmbito dos serviços de saúde. Dessa forma, o cuidado em saúde bucal passa a exigir a conformação de uma equipe de trabalho que se relacione com usuários e que participe da gestão dos serviços para dar resposta às demandas da população e ampliar o acesso às ações e serviços de promoção, prevenção e recuperação da saúde bucal, por meio de medidas de caráter coletivo e mediante o estabelecimento de vínculo territorial. (Ministério Da Saúde, 2012).

Em relação à conduta frente ao aparecimento de algum sintoma, $44 \%$ dos entrevistados informaram que apenas acompanharam a evolução, sem procurar um cirurgião-dentista, 27\% procurou um médico, $17 \%$ fez a automedicação e apenas $12 \%$ procurou um cirurgião-dentista. Esses dados diferem dos resultados encontrados na pesquisa realizada por Vasques (2010), onde relataram que, em relação às atitudes tomadas pelas mães na tentativa de solucionar os problemas surgidos durante a erupção dos dentes decíduos, das 130 participantes que informaram problemas, 56,92\% procuraram o médico pediatra e 11,53\% fizeram automedicação. A visita ao Odontopediatra, com o intuito de buscar solução para os problemas relacionados à erupção dos dentes, foi citada por apenas $10 \%$ das entrevistadas.

Segundo Leung (1989) há grande controvérsia existente na literatura sobre a erupção de dentes decíduos ser ou não o agente etiológico de transtornos como febre, diarreia, úlceras cutâneas, bronquite ou outros teria algumas razões. A primeira e principal delas seria o fato de que a maioria das informações é conseguida através da opinião subjetiva dos pais, que é influenciada pela vontade de explicar mudanças comportamentais através de um diagnóstico com baixa ansiedade. Num segundo ponto, no período dos 30 primeiros meses de vida, que compreende a erupção dos dentes decíduos, é difícil separar os sintomas da erupção daqueles da fisiologia normal ou ainda das mudanças psicológicas das crianças, como as insônias dos 6 meses de idade ou o fato de babar excessivamente dos 3 aos 4 meses. A terceira razão seria a dificuldade de realizar estudos controlados de acompanhamento da erupção e por último está o fato de que a maioria dos estudos passados foi realizada em populações altamente selecionadas.

As variáveis dos estudos são de difícil controle e representam as dificuldades que envolvem essa temática, quando se trata da sintomatologia na erupção dentária (Andrade \& Katz, 2018). Em relação a sintomatologia, quando a intervenção não 
puder ser realizada por um único profissional, sugere-se que as demais especialidades sejam contactadas, e seja tomada uma conduta multidisciplinar (Ventura, 2018).

O presente trabalho apresentou algumas limitações, dentre elas o nível de escolaridade dos responsáveis, o que dificultou em parte a coleta de dados e a ausência no questionário de importantes sintomas como coceira e mordida, sintomatologia já relatada em estudos anteriores.

\section{Conclusão}

Diante dos resultados do estudo, é possível concluir que as manifestações locais e sistêmicas mais comuns durante a erupção dos elementos decíduos foram aumento da salivação, febre e diarreia. O maior percentual de sintomatologia durante o irrompimento dentário aconteceu na faixa etária entre 4 meses à 1 ano.

Em relação à conduta frente ao aparecimento de algum sintoma, os responsáveis informaram que apenas acompanharam a evolução, sem procurar um cirurgião-dentista. É fundamental que estudos longitudinais sejam feitos para o melhor esclarecimento desse tema.

\section{Referências}

Abujamra, C. M., Ferreira, S. L. V., \& Guedes-Pinto, A. C. (1994). Manifestações sistêmicas e locais durante a erupção dos dentes decíduos. Rev Bras Odontol. 51 (1), 6-10.

Andrade, M. T. V., \& Katz, C. R. T. 2018. Relação entre a erupção dos dentes decíduos e manifestações locais e/ou sistêmicas: revisão integrativa. Arq Odontol, Belo Horizonte, 54 (12), 1-8.

Andrade, M. T. V., \& Katz, C. R. T. 2018. Relação entre a erupção dos dentes decíduos e manifestações locais e/ou sistêmicas: revisão integrativa. Arq Odontol, Belo Horizonte, 54 (12), 1-7.

Assed S. Erupção dental.2005. In: Odontopediatria: bases científicas para a prática clínica: Artes Médicas.

Baume, L. J, Becks, H., \& Evans, H. M. L. 1954. Hormonal control of tooth eruption. The effect of thyroidectomy on the upper rat incisor and the response to growth hormonal, thyroxin, or combination of both. $J$ Dent Res. 33, 80-90.

Baume, L.J. 1953. Physiological tooth migration and its significance for the development od occlusion: the biogenetic course of deciduous dentition. $J$ Dent Res, 29, 123-131.

Bellows, C. G., Melcher, A. H., \& Aubin, J. E. 1983. An "'in-vitro" model for tooth eruption utilizing periodontal ligament fibroblasts and collagen lattices. Rev Arch Oral Biol. 28, 715-733.

Benett, H. J., \& Spencer, B. $1986 . \quad$ The teething virus. PediatrInfectDis. $\quad$ 399-401. Bengston, A. L., \& Bengston, N. G. 1994. Diarreia e febre associadas ao irrompimento de dentes decíduos. Ver Assoc Paul Cir Dent. 48, 1271-1275. Bengtson N. G., Bengtson A. L., \& Piccinini D. P. F. 1988. Erupção dos dentes decíduos: sintomas gerais apresentados. RevGauchaOdontol. $36,401-405$. Carpenter, J. V. 1978. The relationship between teething and systemic disturbances. J DentChild. 381-384.

Castro, L. A., Teixeira, D. L. S, \& Modesto, A. 2002. A influência do perfil materno na saúde bucal da criança: relato de caso. J Bras Odontopediatria odontol. Bebê. Curitiba. 5; (23), 70-74.

Cavalcanti, A. L., Carvalho, L. F., Pereira, L. L., Medeiros, A. D., Valença, A. M. G., \& Duarte, R. C. 2002. Primeira consulta odontológica: percepções dos cirurgiões-dentistas quanto ao período ideal. J Bras Odontopediatr Odontol Bebê, Curitiba, 5 (27), 420-424.

Coreil J., Price L., \& Barkey N. 1995. Recognition and management of teethindiarrhea among Florida pediatricians. ClinPediatrics. 34 (11), $591-598$.

Crispin, A. S. A., Duarte, D. A., \& Bonecker, M. 1997. Manifestações locais e sistémicas durante a erupção dentária decídua. RevOdontUniv Santo Amaro. 2 (3) $8-11$.

Ferreira, F. V., Machado, M. V. S., Ardenghi, T. M., \& Praetzel, J. R. 2009. Manifestações Sistêmicas e/ou Locais Associadas à Erupção dos Dentes Decíduos: Estudo Retrospectivo. Pesq BrasOdontoped Clin Integr João Pessoa. 9 (2), 235-239.

Ferreira, S. H., Kramer, P. F., \& Longoni, M. B. 1999. Idade ideal para a primeira consulta odontológica. Rev Gaúcha Odont, Porto Alegre. 47 (4), 236-238.

Fonseca, Y. P., Sant'Anna, G. R., \& Suga, S. S. 1992. A $1^{\text {a }}$ visita ao consultório dentário. RevAssoc Paul CirDent, São Paulo. 46 (4), $825-827$.

Galili, G., Rosenzweig, K. A., \& Klein, H. 1969. Eruption of primary teeth and general pathologic conditions. ASDC. J DentChild. $36,51-54$. 
Research, Society and Development, v. 10, n. 4, e0210413765, 2021

(CC BY 4.0) | ISSN 2525-3409 | DOI: http://dx.doi.org/10.33448/rsd-v10i4.13765

Honing, P. J. 1975. Teething - are today's Pediatricians using yesterday's notions? J Pediat. 87, 415-417.

Jaber, L., Cohen, I. J., \& Mor, A. 1992. Fever associated with teething. Arch Dis Child. 67, 233-234.

Koch, G., Mooder, T., Pousen, S., \& Rasmussen, P.1995. Odontopediatria: uma abordagem clínica: Ed. Santos; 2.

Kugelmass, I. N. 1960. Teething: mechanism and manifestations. N Y State Dent. 26, 469-70.

Leung, A. K. C. 1989. Theething. Am FamPhysician. 39 (2), 131-134.

Macknin, M. L., Piedmonte, M., Jacobs, J., \& Skibinski, C. 2000. Symptoms associated with infant teething: a prospective study. Pediatrics. 105, 747-752.

Massler, M., \& Schour, I. 1941. Studies in thooth development: theories of eruption. Am J Orthodont Oral Surg. 27, 552-576.

Mcintyre, G. T., \& Mcintyre, G. M. 2002. Teething troubles? Br Dent J. 192, 251-255.

Ministério da Saúde, Secretaria de Atenção à Saúde. 2012. Estratégia Saúde da Família: Equipe de Saúde Bucal. Departamento de Atenção Básica Edificio Premium SAF Sul- Quadra2 - Lotes 5/6 Bloco II - Subsolo - CEP: 70.070-060 Brasilia-DF.

Neaderland, R. 1952. Teething: a review. J DentChild. 19, 127-132.

Noronha, J. C. 1985. Erupção dos dentes decíduos e suas manifestações na criança. ArgCentEstudOdont, UFMG. $22,53-64$.

Pinto, G. A.C. 1998. Odontopediatria: Ed. Santos; 1998;

Rocha, L. V. A., Rocha N. M. O., Bullegon, A. C., \& Perachi, M. I. 1988. Erupção dos dentes decíduos: possíveis manifestações locais e gerais. RGO, Porto Alegre. 36, 461-463.

Saito, S. K., Deccico, H. M. U., \& Santos, M. N. 1999. Efeito da prática de alimentação infantil e de fatores associados sobre a ocorrência da cárie dental em pré-escolares de 18 a 48 meses. Revista Odonto Univ. São Paulo, 13 (1), 5-11.

Seward, M. H. 1971. Local disturbances attributed to eruption of the human primary dentition. Br Dent. 130, $72-77$.

Seward, M. H. 1972. General disturbances attributed to eruption of the human primary dentition. ASDC.J DentChild. 39, 178-183.

Silva, K. T. S, \& Walter, L. R. F. 1997. Sinais e sintomas relacionados com a erupção dos dentes decíduos. Anais do 11 Encontro Nacional de Odontologia para Bebês, Londrina- BR. 37.

Tanasen, L. 1968. General and local effects of eruption of deciduos teeth. AnnalesPeediatriaeFenniae. 14 (1), 5-37.

Vasques, E. 2010. Manifestações relacionadas à erupção dentária na primeira infância - percepção e conduta de pais. RFO, Passo Fundo. 15, $124-128$.

Ventura, S. 2018. A importância da equipe multidisciplinar no manejo clínico frente à alteração na cronologia de irrupção. Revista Rede de Cuida dos em Saúde, 12 (1), 1-9.

Walter, L. R. F. 1995. Bebê-clínica: um sonho que se tornou realidade. J Aboprev. 6, 2. 